FEDERAL RESERVE BANK of ST. LOUIS

\section{RESEARCH DIVISION} Working Paper Series

\title{
The Effect of Underreporting on LIBOR Rates
}

\author{
Andrea Monticini \\ and \\ Daniel L. Thornton \\ Working Paper 2013-008A \\ https://doi.org/10.20955/wp.2013.008
}

February 2013

\author{
FEDERAL RESERVE BANK OF ST. LOUIS \\ Research Division \\ P.O. Box 442 \\ St. Louis, MO 63166
}

The views expressed are those of the individual authors and do not necessarily reflect official positions of the Federal Reserve Bank of St. Louis, the Federal Reserve System, or the Board of Governors.

Federal Reserve Bank of St. Louis Working Papers are preliminary materials circulated to stimulate discussion and critical comment. References in publications to Federal Reserve Bank of St. Louis Working Papers (other than an acknowledgment that the writer has had access to unpublished material) should be cleared with the author or authors. 


\title{
The Effect of Underreporting on LIBOR Rates
}

\author{
Andrea Monticini and Daniel L. Thornton \\ Catholic University, Milan Italy \\ and \\ Federal Reserve Bank of St. Louis, St. Louis, Missouri USA
}

February 4, 2013

\begin{abstract}
On May 29, 2008, the Wall Street Journal reported that several large international banks were reporting unjustifiably low LIBOR rates. Since then two large banks, Barclays and UBS, have paid significant fines for manipulating their LIBOR rates, and additional banks are expected to be fined. This paper investigates whether the underreporting of LIBOR rates by some banks significantly affected the reported LIBOR rate by testing whether there was a significant change in the relationship between the LIBOR rate and another rate that reflects the default risk of banks.
\end{abstract}

Keywords: LIBOR rate; default risk; structural breaks

JEL Codes: G10, E43, E44

The views expressed are those of the authors and do not necessarily represent the views of the Federal Reserve System, the Board of Governors, or the regional Federal Reserve Banks. We thank Rosa Abrantes-Metz, Angelo Baglioni, Ettore Croci, and David VanHoose for useful suggestions. 


\section{Introduction}

LIBOR stands for "London interbank offered rate." LIBOR rates were first published by the British Bankers' Association in 1986. Currently LIBOR rates are calculated by Thomson Reuters for ten currencies with 15 maturities ranging from overnight to 12 months. LIBOR rates play an important role in financial markets. Exchanges such as LIFFE and Chicago Mercantile Exchange trade derivatives based on the LIBOR. The British Bankers' Association estimates that financial swaps worth $£ 225$ trillion and loans totaling £6.4tn are indexed to LIBOR. Consequently, understatement of LIBOR rates can generate sizable wealth transfers from lenders to borrowers.

LIBOR rates are not based on transactions data but rather are calculated from the responses of contributing banks to the following question: "At what rate could you borrow funds, were you to do so by asking for and then accepting inter-bank offers in a reasonable market size just prior to 11 am?" The banks' responses are submitted between 11:00 a.m. and 11:10 a.m. and LIBOR rates are released at noon. A LIBOR rate scandal erupted on May 29, 2008, when the Wall Street Journal (WSJ) reported a marked divergence between the LIBOR rate and the WSJ's calculation of the rate in the default insurance market. Subsequently, two large banks, Barclays and UBS, have paid significant fines for underreporting their LIBOR rates; other banks are expected to be fined. This essay investigates whether the apparent fraud by some banks significantly affected the reported LIBOR rates.

Banks have an incentive to understate their LIBOR rates because LIBOR is thought to reflect the default risk associated with interbank lending. ${ }^{1}$ A bank that wants to appear more financially sound than it is has an incentive to underreport its LIBOR rates. Another reason to manipulate the LIBOR is to alter derivative payments (e.g., on Interest Rate Swap contracts). The underreporting by a few banks need not have a significant effect on reported LIBOR rates because each published rate is an average of the submitted rates after the highest and the lowest 25 per cent of the rates have been deleted. This paper investigates whether underreporting of LIBOR rates by 
some banks significantly reduced the reported LIBOR rate by testing whether there was a statistically significant change in the relationship between the published LIBOR rate and another measure of banks' default risk, the rate of large Certificates of Deposit (CDs). ${ }^{2}$ Term CDs and interbank lending are alternative ways for banks to finance lending. Large CDs were not insured, thus both LIBOR and CD rates reflect banks' default risk.

\section{The Methodology}

If underreporting of LIBOR rates by some banks affected the published LIBOR rates, there should be a marked reduction in the spread between published LIBOR rates and rates on equivalentterm marketable CDs. If the underreporting of LIBOR rates by some banks affected the published LIBOR rate, there should be a statistically significant reduction in the spread around the time when some banks were underreporting their LIBOR rates. Alternatively, if the underreporting had little or no effect on the published LIBOR rates no statistically significant change in the spreads should be seen. Hence, we examine whether the apparent fraud by some banks had a significant effect on reported LIBOR rates by investigating whether there was a marked change in the spread between equivalent-term LIBOR and CD rates.

We test for significant changes in the LIBOR - CD spread using Bai and Perron's (1998) test for multiple structural breaks. ${ }^{3}$ Specifically, we estimate the equation

(1) $s_{t}=\alpha+\varepsilon_{t}$,

where $s_{t}$ denotes the LIBOR - CD spread, $\alpha$ is a constant, and $\varepsilon_{t}$ is a random variable with mean zero. The variance of $\varepsilon_{t}$ need not be constant; however, breaks in variance are permitted only if they occur on the same dates as the breaks in $\alpha .{ }^{4}$ The number and dates of the breaks are assumed to be unknown. If the Bai and Perron test reveals significant structural breaks in the spread, the

\footnotetext{
2 Abrantes-Metz et al. (2012) investigate whether manipulation of LIBOR rates occurred during the period January 2 , 2007 through June 1, 2008, by looking for anticompetitive market behaviour of the participating banks. They find statistical evidence of patterns that appear inconsistent with those expected to occur under market competition but no evidence that LIBOR rates were manipulated downward as suggested by the WSJ's analysis.

${ }^{3}$ The F-tests are performed sequentially, e.g., 0 versus 1 break, 1 versus 2 , and so on.

${ }^{4} \varepsilon_{t}$ may also be serially correlated.
} 
magnitude of the breaks are assessed by estimating the equation

(2) $s_{t}=\alpha+\beta_{i} D_{i}+\varepsilon_{t}$,

where $D_{i}$ denotes a dummy variable for the $i^{\text {th }}$ statistically significant structural break; $D_{i}$ is 1 for the period after the structural break and zero otherwise. The coefficient $\beta_{i}$ denotes the size of the mean shift. The data are daily and cover the period January 2, 2004 through December 31, 2010. Lehman Bros.' announcement on September 15, 2008, had a significant but apparently temporary effect on a variety of rate spreads, including LIBOR - CD spreads, so the observations from September 15 through October 15, 2008 are deleted. This should not affect the conclusions because the underreporting of the LIBOR rates should reduce the average LIBOR - CD spread for a period much longer than a few months. The analysis is done using both the 1-month and 3-month LIBOR and $\mathrm{CD}$ rates.

\section{The Findings}

The results of the Bai and Perron test for the 1- and 3-month spreads are reported in Table 1. There were three statistically significant breaks in the 1-month spread and four in the 3-month spread. ${ }^{5}$ The magnitude of the break is expressed in basis points, and the standard errors were obtained using a heteroskedasticity autocorrelation consistent (HAC) covariance matrix estimator with the Bartlett kernel.

The first two breaks in the rate spreads are similar in magnitude, about -1.5 basis points and -4 basis points, respectively. The first break for the two spreads occurs nearly a year apart-June 14 , 2005 for the 3-month spread and June 23, 2006 for the 1-month spread. The first break in the 3month spread is consistent with evidence that Barclays began manipulating its dollar LIBOR rates in $2005 .{ }^{6}$ While the first statistically significant break in the 1-month spread did not occur until a year later, the average 1-month spread had declined substantially by June 14, 2005: it averaged 5.1 basis points from January 2, 2004 through January 5, 2005, to 4.65 basis points from January 5,

\footnotetext{
${ }^{5}$ All breaks are statistically significant at $1 \%$ level. The trimming parameter has been set equal to 0.15 as suggested by Bai and Perron (2003).

${ }^{6}$ See BBC News for a list of important LIBOR scandal dates, http://www.bbc.co.uk/news/business-18671255.
} 
2005 through June 14, 2005-a reduction of 45 basis points. By June 23, 2006-the date identified by the Bai and Perron test—-the average declined by an additional 68 basis points.

The second break in the series occurred much closer together. The break in the 3-month spread occurred before the outset of the financial crisis, August 9, 2007, while the break in the 1month spread occurred about two months after the financial crisis began. The fact that the first break occurred prior August 9 is not surprising because banks appeared to have been manipulating their LIBOR rates well in advance of the onset of the financial crisis. Besides, there were a number of indicators that there were problems with mortgage-back securities before July $2007 .^{7}$ In any event, the estimates suggest that the LIBOR rates declined about 4 basis points relative to the corresponding $\mathrm{CD}$ rates. Hence, both rate spreads suggest that the underreporting by some banks affected the published LIBOR rates.

The third break in the 3-month spread, which occurred on December 3, 2008, was very large, more than offsetting the sum of the two previous negative breaks. The third break in the 1month spread occurred about three months later, on March 11, 2009. The break was positive and essentially offset the two previous negative breaks. Indeed, the hypothesis that the sum of the three breaks is zero cannot be rejected at even the 10 per cent significance level. Both of these breaks occurred as furor over the underreporting by some banks intensified. Indeed, the break in the 3month spread came on the heels of the release of a draft document by the British Banks' Association on November 17, 2008: The document (i) outlined how bank's LIBOR rates should be set and (ii) required contributing banks to audit their rate submission procedures. Hence, these results suggest that banks stopped underreporting their LIBOR rates as the scandal intensified. In the case of the 3month spread banks appear to have overreacted; however, the 3-month spread returned to its preunderreporting level until late 2009: The hypothesis that the sum of the four coefficients is zero cannot be rejected at any reasonable significance level.

\footnotetext{
${ }^{7}$ See, "The Financial Crisis: A Timeline of Events and Policy Actions, Federal Reserve Bank of St. Louis, at http://timeline.stlouisfed.org/pdf/CrisisTimeline.pdf.
} 


\section{Discussion and Conclusion}

There is growing evidence that some banks intentionally underreported their LIBOR rates to appear more financially sound and to make additional profits. Because the published LIBOR rates are calculated after deleting the highest and lowest 25 per cent of the rates contributed by the panel, it is unclear whether the underreporting materially affected published LIBOR rates. Previous research has produced mixed results. Snider and Youle (2010) find evidence in favour of Libor manipulation based on panel data regressions, while Abrantes-Metz et al. (2012) finds some evidence of anticompetitive market behavior by the participating banks. Like us, Kuo et al. (2012) compare LIBOR rates to other bank funding measure like Federal Reserve's Term Auction Facilities (TAF). They use panel data analysis over the period 2007:01:01 - 2009:03:31 imposing a-priori some breaks for the crisis periods. As complementary evidence, they compare the LIBOR to other funding cost indexes like the eurodollar and the secondary market for credit default swaps. They find some deviations of LIBOR, but they do not conclude that this resulted in a misreporting of LIBOR. We investigate this issue by testing for structural breaks in the spread between termequivalent LIBOR and CD rates using daily data for the period January 2, 2004, through December 31, 2010. We find evidence consistent with the hypothesis that the underreporting of the LIBOR rates by some banks reduced the reported LIBOR rates. Specifically, we find that the average of 1and 3-month LIBOR - CD spreads declined by nearly 5.5 basis points by mid-2007. We also find that the LIBOR - CD spreads eventually returned to their pre-underreporting levels. 


\section{References:}

Abrantes-Metz, R.M., Kraten, M., Metz, A.D., and Seow, G.S. (2012). “LIBOR Manipulation?” Journal of Banking and Finance, 36, 136 - 150.

Abrantes-Metz, R., Villas-Boas, S., and Judge, G. (2011). "Tracking the Libor Rate", Applied Economics Letters 18 (19), 893 -899.

Andrews D., Monahan C. (1992). "An improved heteroskedasticity and autocorrelation consistent covariance matrix estimator" Econometrica, 60, 953-966.

Bai, J., and Perron, P. (1998), "Testing for and Estimation of Multiple Structural Changes" Econometrica, 66, 47-79.

Bai, J., and Perron, P. (2003), "Computation and Analysis of Multiple Structural Changes" Journal of Applied Econometrics, 18, 1-22.

Kuo, D., Skeie, D., and Vickery, J. (2012). A comparison of Libor to other measures of bank borrowing costs. Working Paper http://www.newyorkfed.org/research/economists/vickery/LiborKSV staff webpage.p $\underline{\mathrm{df}}$

Snider, C., Youle, T. (2010). "Does the Libor Reflect Banks' Borrowing Cost?”, Working Paper, UCLA.

Thornton, Daniel L. (2009). "What the LIBOR-OIS Spread Says," Federal Reserve Bank of St. Louis Economic Synopses, 2009, No. 24.

Thornton, Daniel L. (2010). "Can the FOMC Increase the Funds Rate Without Reducing Reserves? Federal Reserve Bank of St. Louis Economic Synopses, 2010, No. 28. 
Table 1: Estimates of Equation 2 for the 1- and 3-Month LIBOR - CD Spreads

\begin{tabular}{|c|c|c|c|c|}
\hline & \multicolumn{2}{|c|}{ 1-Month Spread } & \multicolumn{2}{|c|}{ 3-Month Spread } \\
\hline & Coef. & Break Date & Coef. & Break Date \\
\hline$\alpha$ & $\begin{array}{l}4.795^{*} \\
(0.11)\end{array}$ & & $\begin{array}{l}5.452^{*} \\
(0.16)\end{array}$ & \\
\hline$\beta_{1}$ & $\begin{array}{c}-1.742 * \\
(0.21)\end{array}$ & 2006:06:23 & $\begin{array}{c}-1.283^{*} \\
(0.18)\end{array}$ & 2005:06:14 \\
\hline$\beta_{2}$ & $\begin{array}{c}-3.849^{*} \\
(0.65)\end{array}$ & 2007:11:02 & $\begin{array}{c}-4.319^{*} \\
(0.99)\end{array}$ & 2007:07:02 \\
\hline$\beta_{3}$ & $\begin{array}{l}4.441^{*} \\
(0.69)\end{array}$ & 2009:03:11 & $\begin{array}{c}13.878 * \\
(1.746)\end{array}$ & 2008:12:03 \\
\hline$\beta_{4}$ & -- & -- & $\begin{array}{c}-10.547 * \\
(1.59)\end{array}$ & 2009:12:14 \\
\hline $\bar{R}^{2}$ & \multicolumn{2}{|c|}{0.292} & \multicolumn{2}{|c|}{0.434} \\
\hline
\end{tabular}

daily data for the 2004:01:02 - 2010:12:31 period. $\left(^{*}\right)$ denotes statistical significance at the 1 per cent level based on HAC standard errors, in parentheses. The sample size is 1,687. 